\title{
Mature Ovarian Teratoma
}

National Cancer Institute

\section{Source}

National Cancer Institute. Mature Ovarian Teratoma. NCI Thesaurus. Code C8112.

An ovarian teratoma which may be cystic, composed entirely of well differentiated, adulttype tissues, without evidence of fetal-type tissues. 